\title{
Perkütan koroner girişim yapılmış gerçek yaşam hastalarında ikili antitrombosit tedavi kullanımının PRECISE-DAPT, DAPT skorlarına göre değerlendirilmesi ve bu skorların stent trombozu, ciddi kanama ile ilişkisi
}

\author{
Evaluation of the use of dual antiplatelet therapy according to PRECISE-DAPT and \\ $D A P T$ scores in real-life patients undergoing percutaneous coronary intervention and \\ their relationship with stent thrombosis and severe bleeding
}

Evrim Şimşek, Yavuz Selim Kılıç, Azem Akılıı

\begin{abstract}
Özet
Amaç: Perkütan koroner girişim (PKG) sonrası ikili antitrombosit tedavi (IATT) süresinin belirlenmesinde PRECISE-DAPT ve DAPT skorlarının kullanı Imasını önerilmektedir. Bu risk skorlarının gerçek yaşam validasyonu ise bulunmamaktadır. Gerçek yaşam pratiğinde PKG sonrası IATT alan hastaların tedavi sürelerinin risk skorlarına göre değerlendirilmesi, stent trombozu ve ciddi kanama ile bu risk skorlarının ilişkisinin araştırılması amaçlanmıştır.

Gereç ve yöntem: Ocak-Mayıs 2019 tarihleri arasında çalışma merkezine başvuran en az 1 yıl önce PKG yapılmış hastalar incelenmiştir. Hastaların kullandıkları IATT süreleri, takip süresi içinde gelişen stent trombozu ve ciddi kanama $(B A R C \geq 3$ ) olayları sorgulanmış ve gruplar arasında PRECISE-DAPT ile DAPT skorları karşılaştırılmıştır.

Bulgular: Çalışmaya 366 hasta dahil edilmiştir. Ortalama takip süresi $17,57 \pm 4,8$ aydır. Hastaların ortalama yaşı $61 \pm 11$ ve \%54,4'ü kadındı. Hastaların \%81,4'ü akut koroner sendrom (AKS) tanısına sahipti. Stent trombozu olan $20(\% 5,5)$ hasta saptanmıştır. Ciddi kanama $17(\% 4,6)$ hastada izlenmiştir. Stent trombozu olaylarının \%70 (14)'i 1. yılın sonunda gelişmiştir. Bu hastaların 12'si yüksek DAPT, düşük PRECISE-DAPT skoruna sahipken sadece 2'si IATT alırken; 10'u tek asetilsalisilik asit almaktaydı. Ciddi kanama hastaların \%4,6 (17)'sında gelişmiştir. Hastalardan 15'i yüksek PRECISE-DAPT skoruna sahipti ve 10'u 6 aydan uzun IATT alırken kanama gerçekleşmiştir. Kanama gelişen hastaların ortalama PRECISE-DAPT skoru anlamlı olarak daha yüksekti. $(40,59 \pm 14,7$ 'e karşı 23,80 20 p<0,001) Tromboz gelişen hastalarda da DAPT skoru anlamlı olarak daha yüksekti. $(3,10 \pm 1,25$ 'e karşı 1,81 $\pm 1,27 p<0,001)$

Sonuç: PRECISE-DAPT ve DAPT skorları PKG uygulanmış IATT altındaki gerçek yaşam hastalarında da sırasıyla artmış kanama ve stent trombozu ile ilişkilidir. Günlük pratikte hastalarda IATT süresi belirlenirken mevcut skorların kullanılması hastaların gereksiz uzun ya da kısa İATT almasını ve kötü sonlanımları önleyebilir.
\end{abstract}

Anahtar kelimeler: İkili antitrombosit tedavisi, risk skorları, kanama, stent trombozu.

Şimşek E, Kılıç YS, Akıllı A. Perkütan koroner girişim yapılmış gerçek yaşam hastalarında ikili antitrombosit tedavi kullanımının PRECISE-DAPT, DAPT skorlarına göre değerlendirilmesi ve bu skorların stent trombozu, ciddi kanama ile ilişkisi. Pam Tıp Derg 2020;13:137-147.

\footnotetext{
Abstract

Purpose: PRECISE-DAPT and DAPT scores are recommended to determine the duration of dual antiplatelet therapy (DAPT) after percutaneous coronary intervention $(\mathrm{PCl})$. There is no real-life validation of these risk scores. The aim of this study was to evaluate the duration of treatment according to risk scores and to investigate the relationship between stent thrombosis, severe hemorrhage and these risk scores.

Materials and methods: Patients who had undergone PCl at least 1 year ago and admitted to study centre between January-May 2019 were evaluated for the study. DAPT duration, stent thrombosis, severe hemorrhage $(B A R C \geq 3$ ) events were investigated and PRECISE-DAPT, DAPT scores were compared between the groups. Results: Three hundred and sixty-six patients were included in the study. Mean follow-up was $17.57 \pm 4.8$ months, mean age was $61 \pm 11$ and $54.4 \%$ of the patients were female. $81.4 \%$ of the patients had acute coronary syndrome. $5.5 \%(20)$ of them had stent thrombosis. 14 of the stent thrombosis occurred 1 year after $\mathrm{PCl}$. Even 12 of these patients had high DAPT and low PRECISE-DAPT scores, only 2 received DAPT; 10 of them were taking only acetylsalicylic acid. $4.6 \%$ (17) of the patients had severe bleeding and 15 of them had a high PRECISE-DAPT score and 10 of them had bleeding while receiving DAPT for more than 6 months. The mean

Evrim Şimşek, Uz. Dr. Ege Üniversitesi Tıp Fakültesi Kardiyoloji Anabilim Dalı, Bornova/iZMiR, e-posta: drevrimsimsek@gmail.com, (orcid. org/0000-0003-3183-8060) (Sorumlu yazar)

Yavuz Selim Kılıç, Dr. Ege Üniversitesi Tıp Fakültesi Kardiyoloji Anabilim Dalı, Bornova/IZMiR. e-posta: yavuzselim_23@hotmail.com (orcid. org/0000-0003-4250-2087)

Azem Akıllı, Prof. Dr. Ege Üniversitesi Tıp Fakültesi Kardiyoloji Anabilim Dalı, Bornova/IZMiR. e-posta: azem.akilli@ege.edu.tr (orcid.org/00000003-1383-8024)
} 
PRECISE-DAPT score of the patients with bleeding was significantly higher. $(40.59 \pm 14.7 \mathrm{vs.} 23.80 \pm 20 p<0.001)$ DAPT score was also significantly higher in patients with thrombosis. $(3.10 \pm 1.25$ vs. $1.81 \pm 1.27 p<0.001)$

Conclusion: PRECISE-DAPT and DAPT scores are associated with increased bleeding and stent thrombosis also in real-life patients, respectively. During clinical practice, the use of current scores for DAPT duration may prevent unnecessary long or short treatment periods and this approach could prevent poor outcomes.

Key words: Dual antiplatelet therapy, risk scores, bleeding, stent thrombosis.

Şimşek E, Kılıç YS, Akıllı A. Evaluation of the use of dual antiplatelet therapy according to PRECISE-DAPT and DAPT scores in real-life patients undergoing percutaneous coronary intervention and their relationship with stent thrombosis and severe bleeding. Pam Med J 2020;13:137-147.

\section{Giriş}

Stent trombozunu önlemek için asetilsalisilik asit (ASA) ve trombositlerde yer alan P2Y12 reseptörlerini bloke eden ilaçlar, perkütan koroner girişim sonrası ikili anti trombosit tedavi (IATT) protokolü olarak her hastaya önerilmektedir [1]. Bu tedavi protokolü ile trombotik komplikasyonlar azaltılsa da ciddi kanamalarla ilişkili komplikasyonlar artmaktadır. IATT ilişkili kanama sağ kalımda azalma, yaşam kalitesinde düşüş ve artmış sağlık harcamaları ile ilişkilidir [2-4]. Sadece Avrupa'da yılda 1,5 milyondan fazla kişiye IATT başlanmaktadır. Çok sayıda hastayı ilgilendiren bu durum için de sayısız çalışma yapılmıştır. İki yüz binden fazla hastayı içeren 30 'dan fazla randomize klinik çalışmada IATT tedavinin etkinliği ve işlem sonrası ne kadar süreyle kullanılması gerektiği araştırılmıştır, ancak henüz her hastaya uygulanabilecek ideal IATT için süre belirtilememiştir [1].

IATT süresi belirlenirken her hastanın kendi özelinde kanama ve tromboz risklerinin göz önüne alınması faydalı olacaktır [5-8]. Avrupa kardiyoloji derneği (ESC) IATT kılavuzunda hastaların tedavi süresini belirlemek üzere geliştirilen, kanama riskini değerlendirmek için PRECISE-DAPT (Predicting bleeding complications in patients undergoing stent implantation and subsequent dual antiplatelet therapy) skorunun, 1 yıldan uzun süre IATT kullanılması kararı için özellikle stent trombozu riski yüksek, kanama riski düşük hastaları belirlemede DAPT (Dual antiplatelet therapy) skorunun kullanılmasını sınıf $2 b$ öneri düzeyi ile önermektedir [1]. Genel olarak akut koroner sendrom (AKS) hastalarında 12 ay, kararlı angina nedeniyle stent takılan hastalarda ise 3-6 ay İATT kullanılması önerilirken; DAPT skoru yüksek hastalarda 1 yıldan uzun, PRECISEDAPT skoru yüksek hastalarda ise belirtilen sürelerin mümkün olan en alt sınırında IATT kullanılması önerilmektedir [1].

PRECISE-DAPT skoru birçok klinik çalışmanın verileri kullanılarak oluşturulmuş ve başka randomize kontrollü çalışma sonuçları kullanılarak bu skorun etkinliği doğrulanmaya çalışılmıştır [4]. DAPT skoru da benzer şekilde randomize kontrollü DAPT çalışması verileri kullanılarak üretilmiş ve başka bir klinik stent çalışması verileri kullanılarak doğrulanmıştır [9]. IATT hakkında birçok klinik çalışma yapılmış olsa da bu skorlar başka klinik çalışmalarda kullanılmamıştır ve bu skorların en temel eksikliği gerçek yaşam hastalarında kötü sonlanımlarla iliş̧ilerinin doğrulanmamış olmasıdır [1]. Oysa gerçek yaşam hastaları ve onların klinik takipleri randomize çalışmalardan farklılıklar gösterebilmektedir. Bu nedenle kontrollü klinik çalışmalar gerçek yaşam verileri ile kontrol edilmeye çalışılmaktadır.

PRECISE-DAPT skoru ve DAPT skorlarının gerçek yaşamda perkütan koroner girişim yapılmış hastalarda stent trombozu ve ciddi kanamalarla olan ilişkisini araştırmak ve bu hastaların skor sonuçları ile kullanmış oldukları IATT sürelerinin değerlendirilmesi amaçlanmıştır.

\section{Gereç ve yöntem}

Ocak 2019-Mayıs 2019 tarihleri arasında çalışma merkezine başvuran, en az 1 yıl önce perkütan koroner girişim öyküsü olan hastalar incelenmiştir. Çalışmaya dahil edilme kriterlerine uyan hastalar çalışma merkezine çağrılarak ve çalışma hastanesi elektronik hasta bilgi sistemi üzerindeki kayıtları araştırılarak olgu rapor formları doldurulmuştur. Atriyal fibrilasyon ya da başka bir nedenle oral antikoagulan kullanan, koroner anjiyografi görüntülerine ya da raporlarına ulaşılamayan, herhangi bir operasyon nedeniyle planlı olarak antitrombosit 
tedavisine ara verilen ve bilgilendirilmiş gönüllü olur formunu imzalamayı kabul etmeyen hastalar çalışmadan dışlanmıştır.

Çalışmaya alınan hastaların koroner girişimden sonra kullandığı antitrombosit tedavileri, kullandıkları süreler (1-6 ay, 7-11 ay, 12 ay, 13 ay üzeri) olgu rapor formuna kaydedilmiştir. PRECISE-DAPT ve DAPT skorları https://www.acc.org/tools-and-practicesupport/mobile-resources/features/dapt-riskcalculator ve http://www.precisedaptscore.com/ predapt/webcalculator.html sayfalarında yer alan resmi hesaplayıcılar kullanılarak hesaplanmıştır $[10,11]$. DAPT skorunda hastanın yaşı, sigara öyküsü, diabetes mellitus (DM), başvuru anında miyokard infarktüsü (Mi) olması, takılan stent çapı, perkütan koroner girişim (PKG) öyküsü, sol ventrikül ejeksiyon fraksiyonu (LVEF) $<\% 30$, venöz grefte stent, kronik böbrek yetersizliği (KBY), hipertansiyon $(\mathrm{HT})$ ve periferik arter hastalığı öyküsü, PRECISE-DAPT skorunda ise yaş, kreatinin klirensi, hemoglobin, lökosit değeri ve kanama öyküsü değerlendirilmektedir. ESC kılavuzunda belirtildiği gibi PRECISE-DAPT skoru $\geq 25$ olanlar kanama açısından yüksek riskli kabul edilirken, DAPT skoru $\geq 2$ olanlar da stent trombozu açısından yüksek riskli kabul edilmiştir $[1,4,9]$.

Hastalarda perkütan koroner girişim sonrası gelişen stent trombozu ve ciddi kanama olayları elektronik hasta dosyalarından ve görüşmeye çağrılan hastaların yanlarında bulunan tıbbi kayıtlar üzerinden değerlendirilmiştir. Stent trombozu, AKS ön tanısı ile yapılan koroner anjiyografi işleminde mevcut stentler üzerinde ya da $5 \mathrm{~mm}$ proksimal veya distalinde tromboze lezyon saptanması olarak değerlendirilirken; olay zamanına göre ilk 24 saat içinde gelişmesi durumunda akut, 24 saat 1 ay içinde ise subakut, 1 ay ile 1 yıl arasında ise geç, 1 yıl üstünde ise çok geç stent trombozu olarak tanımlanmıştır. Ciddi kanama olarak ise Bleeding Academic Research Consortium (BARC) 3 ve üstü kanama olayları kabul edilmiştir [12, 13].

Hastalar IATT kullanım durumu, stent trombozu ve ciddi kanama gelişimi açısından karşılaştırılırken, gruplar arasında PRECISEDAPT ile DAPT skorları arasındaki farklılıklar değerlendirilmiştir.

Çalışma merkezi tıbbi araştırmalar etik kurulundan onay alınmıştır.

\section{İstatistik}

Değişkenlerin normal dağılımı KolmogorovSmirnov testi ile belirlenmiştir. Normal dağılan devamlı değişkenler ortalama ve standart sapma (sd: standart deviation), normal dağılmayan devamlı değişkenler ise ortanca ve minimum-maksimum olarak belirtilirken, kategorik değişkenler yüzde ve olgu sayısı olarak belirtilmiştir. Olay gelişen gruplar karşılaştıııırken devamlı değişkenler için normal dağılım paternine göre $T$ test ya da Mann-Whitney $U$ testi kullanılırken, kategorik değişkenler için ki kare ya da Fisher'in Exact testi kullanılmıştır. Olay gelişen ve gelişmeyen gruplar yüksek DAPT ve PRECISE-DAPT skorları açısından univariate Cox regresyon analizi ile de değerlendirilmiştir. Tüm karşılaştırmalar SPSS (Statistical Package for Social Sciences) v20 (IBM, Armonk, NY, ABD) istatistik paket programı kullanılarak yapılmıştır.

\section{Bulgular}

Ocak 2019-Mayıs 2019 tarihleri arasında 419 hasta çalışma için değerlendirildi. Dahil edilme ve dışlama kriterleri doğrultusunda 366 hasta çalışmaya dahil edildi. Hastaların yaş ortalaması $61 \pm 11$ yıl ve hastaların \%54,4'ü kadındı. Hastaların \%43,4'ü (159) ST segment yükselmeli Mi, \%38'i (139) ST segment yükselmesiz Mi nedeniyle koroner angiografi işlemine alınırken kalan \%18,6 hasta da stabil angina pektoris tanısı ile işleme alınmıştı. HT hastaların \%58'inde bulunurken, \%31,6'sında DM mevcuttu. Daha önce koroner girişim öyküsü hastaların \%20,5'inde bulunurken, \%9'u daha önce gastrointestinal sistem (GIS) kanaması geçirmişti. ASA yanında kullanılan ikinci antitrombosit ilaç olarak hastaların $\% 64,5$ 'i klopidrogel, \%35'i tikagrelor kullanırken, prasugrel sadece $1(\% 0,3)$ hastaya reçete edilmişti. Hastaların \%69,9'unda koroner darlıklar için 2. Jenerasyon everolimus ve zotarolimus içeren ilaç kaplı stent (IKS) uygulanmış idi, kalan hastalarda ise çıplak metal stent (ÇMS) tercih edilmişti (Tablo1).

Hastaların ortalama takip süresi $17,6 \pm 4,8$ ay, ortalama IATT kullanım süresi $11,9 \pm 2,9$ aydır. Hastaların sadece \%15'inin birinci yıl sonrası IATT'ye devam ettiği saptanmıştır. Birinci yıl sonunda hastaların \%77'si sadece ASA tedavisi alırken \%7,2'si sadece klopidogrel kullanmaktaydı. Hastaların risk skorları 
Tablo 1. Hastaların bazal karakteristik özellikleri.

\begin{tabular}{|c|c|}
\hline & Ort \pm SD / \% (n) \\
\hline Takip süre (ay) & $17,57 \pm 4,8$ \\
\hline Yaş (yıl) & $61 \pm 11$ \\
\hline Kadın cinsiyet & $45,6(199)$ \\
\hline $\mathrm{VKI}\left(\mathrm{kg} / \mathrm{m}^{2}\right)$ & $26 \pm 2$ \\
\hline DM & $31,6(116)$ \\
\hline HT & $58,6(218)$ \\
\hline Sigara & $56,6(207)$ \\
\hline Obezite $\left(\mathrm{VKI}>30 \mathrm{~kg} / \mathrm{m}^{2}\right)$ & $9,0(33)$ \\
\hline Hiperlipidemi (LDL>130mg/dl) & $49,1(180)$ \\
\hline Perkütan koroner girişim öyküsü & $20,5(75)$ \\
\hline Mì öyküsü & $19,4(71)$ \\
\hline Sistolik disfonksiyon $(\mathrm{LVEF}<30)(\%)$ & $1,4(5)$ \\
\hline SVO-GİA öyküsü & $4,9(16)$ \\
\hline Kanama öyküsü & $9,0(33)$ \\
\hline KBY (Kreatin>2 mg/dl) & $6(22)$ \\
\hline \multicolumn{2}{|l|}{ Tanı } \\
\hline STEMI & $43,4(159)$ \\
\hline NSTEMI & 38 (139) \\
\hline Kararlı KAH & $18,6(68)$ \\
\hline \multicolumn{2}{|l|}{ Kullanılan P2Y12 inhibitörü } \\
\hline Klopidogrel & $64,5(237)$ \\
\hline Tikagrelor & $35(128)$ \\
\hline Prasugrel & $0,3(1)$ \\
\hline \multicolumn{2}{|l|}{ Diğer medikal tedavi } \\
\hline B-bloker & $69,9(256)$ \\
\hline Ace inh. /ARB & $71,9(263)$ \\
\hline Statin & $89,9(329)$ \\
\hline PPI & $73,5(269)$ \\
\hline \multicolumn{2}{|l|}{ Stent çapı } \\
\hline $3,0 \mathrm{~mm}$ ve üzeri & $54,2(202)$ \\
\hline 3,0 mm'den küçük & $45,8(164)$ \\
\hline Stent uzunluğu (mm) & $20 \pm 6$ \\
\hline İKS & $69,9(256)$ \\
\hline ÇMS & $30,1(110)$ \\
\hline
\end{tabular}

(ACE: Anjiotensin dönüştürücü enzim, ARB: Anjiotensin reseptör blokeri, BMS: Çıplak metal stent, CX:Sirkümfleks arter, DES: Ilaç salınımlı stent, DM, diyabetes mellitus, GIA: Geçici iskemik atak, KAH:Koroner arter hastalığı, KBY: Kronik böbrek yetmezliği, LAD: Sol ön inen arter, LMCA: Ana koroner arter, LVEF: Sol ventrikül ejeksiyon fraksiyonu, NSTEMI: ST segment yüksekliği olmayan miyokard infarktüsü,

PPI: Proton pompa inhibitörü, SVO: Serebrovasküler olay, VKI: Vücut kitle indeksi)

incelendiğinde ortalama PRECISE-DAPT skoru $24 \pm 12$ olarak saptanırken, yüksek riskli olarak tanımlanan skor $\geq 25$ olan hasta oranı \%35,9'dur. Hastaların DAPT skorlarına bakıldığında ortalama skor 1,8 11,3 iken $\% 62,4$ hasta yüksek risk (DAPT $\geq 2$ ) grubundaydı. Her iki skor birlikte değerlendirildiğinde hastaların \%49,2'si düşük PRECISE-DAPT skoruna ve yüksek DAPT skoruna sahipken, \%22,7'si yüksek PRECISEDAPT ve düşük DAPT skorlarına sahipti (Tablo 2). 
Tablo 2. Hastaların PRECISE-DAPT VE DAPT skorları.

\begin{tabular}{lll}
\hline & $\begin{array}{l}\text { DAPT }<2 \\
\mathrm{n}: 137\end{array}$ & $\begin{array}{l}\text { DAPT } \\
\mathrm{n}: 229\end{array}$ \\
\hline $\begin{array}{l}\text { PRECISE-DAPT }<25 \\
\text { n:234 }\end{array}$ & $\% 14,8(54)$ & $\% 49,2(180)$ \\
PRECISE-DAPT $\geq 25$ & $\% 22,7(83)$ & $\% 13,2(49)$ \\
n:132 & & \\
\hline
\end{tabular}

Ciddi kanama (BARC $\geq 3)$ hastaların \%4,6'sında (17) gelişmiştir. BARC 1 ve 2 kanama ise \%7,9 (29) hastada gerçekleşmiştir. Ciddi kanamaların tamamı endoskopi ya da kolonoskopi ile tanısı koyulmuş Gis kanamasıdır. Ciddi kanama olaylarının tamamı ilk bir yıl içinde görülürken (ortalama 7,6 $\pm 3,4$ ay), kanama sırasında hastaların tamamı IATT almaktaydı. Hastalardan 15'i yüksek PRECISEDAPT skoruna sahiptir ve bu hastalardan 10'u 6 aydan uzun IATT tedavisine devam ederken ciddi kanama gerçekleşmiştir. Bir yıldan fazla IATT alırken kanama gelişen tek hastanın ise PRECISE-DAPT skoru yüksekken, DAPT skoru düşüktü (Tablo 3).

Stent trombozu hastaların \%5,5'inde (20) gelişirken, olaylarının \%70'i (14) çok geç, kalan \%30'u (6) ise geç stent trombozudur. (median süre: 14 ay, min.: 6 ay maks.: 21ay). Stent trombozu sırasında hastaların \%40'ı (8) IATT altındaydı. Birinci yıldan sonra gelişen olaylarda IATT'ye devam eden 4 hasta vardı ve kalanların tamamı sadece ASA almaktaydı. Risk skorlarına bakıldığında birinci yıldan sonra stent trombozu gelişen 14 hastanın hepsi düşük PRECISEDAPT skoruna sahipken, 12'si yüksek DAPT skoruna sahipti ve bu hastalardan sadece 2'si birinci yıldan sonra IATT almaktaydı. Birinci yıldan sonra IATT altında stent trombozu gelişen 2 hasta ise düşük DAPT skoruna sahipti.

Ciddi kanaması olan ve olmayan hastalar karşılaştırıldığında yaş, cinsiyet, HT, DM gibi risk faktörleri, IATT dışı temel medikal tedavilerde, girişim endikasyonunun AKS olması, yerleştirilen stent çapı ve İKS oluşu açısından anlamlı bir fark yokken daha önce kanama öyküsü olan hastalarda ciddi kanama anlamlı olarak daha fazlaydı. Gruplar skorlar açısından karşılaştırıldığında ciddi kanama gelişen grupta ortalama PRECISE-DAPT skoru daha yüksek saptandı. $\quad(40,59 \pm 14,7$ 'ye karşı $23,80 \pm 20$ $p<0,001)$ Ayrıca sıklık olarak da yüksek riskli grup olarak tanımlanan PRECISE-DAPT $\geq 25$ olan hastalar ciddi kanama grubunda daha fazlaydı (\%88,2'ye karşı \%33,5 $p<0,001$ ) (Tablo 3). Univariate analizde de yüksek PRECISEDAPT skoru yaklaşık 13 kat artmış ciddi kanama riski ile ilişkili bulunmuştur ( $p<0,001, \mathrm{OR}: 13,85$, \%95 GA 3,168-60,586) (Şekil 1).

Stent trombozu açısından ise hastalar karşılaştırıldığında yaş, cinsiyet, HT, diyabet gibi risk faktörleri, yerleştirilen stent çapı ve İKS oluşu açısından anlamlı bir fark yoktu. Ancak stent trombozu hastalarında sigara içilmesi ve sol inen koroner arter (LAD)'e işlem öyküsü anlamlı olarak daha fazlaydı. (Sigara için $\% 90$ 'a karşı $\% 54,6 p=0,002$, LAD stent $\% 80$ 'e karşı \%42,5 $p=0,027)$ DAPT skoru ortalaması stent trombozu grubunda anlamlı olarak daha yüksekti. $(3,10 \pm 1,25$ 'e karşı 1,81 $\pm 1,27 p<0,001)$ Ayrıca univariate analizlerde de yüksek DAPT skoru olması yaklaşık 5,9 kat artmış risk ile ilişkili saptanmıştır (DAPT için $p=0,017$, OR:5,95, \%95 GA1,382- 25,683) (Tablo 4) (Şekil2).

\section{Tartışma}

Perkütan koroner girişim yapılmış gerçek yaşam hastalarında IATT başlandıktan sonra ciddi kanama gelişen hastalarda PRECISEDAPT skoru, stent trombozu gelişen hastalarda da DAPT skoru anlamlı olarak yüksek bulunmuştur. Ayrıca bu hastalarda 1 yıldan sonra kanama riski düşük (PRECISEDAPT <25) tromboz riski yüksek (DAPT $\geq 2$ ) olmasına rağmen hastalarda yeterli oranda IATT'ye devam edilmemektedir ve IATT kesilen hastalarda stent trombozu daha fazla izlenmiştir. PRECISE-DAPT skoru yüksek olduğu halde IATT 6 aydan daha uzun devam edilen hastalarda da ciddi kanama daha fazla izlenmiştir.

Koroner girişim sonrası başlanan IATT stratejisinde temel basamak ilaçlara bağlı kanama riski ile kesilmesine bağlı stent trombozu ve Mi riski arasındaki dengeyi sağlamaktır. Birçok çalışma IATT süresi 


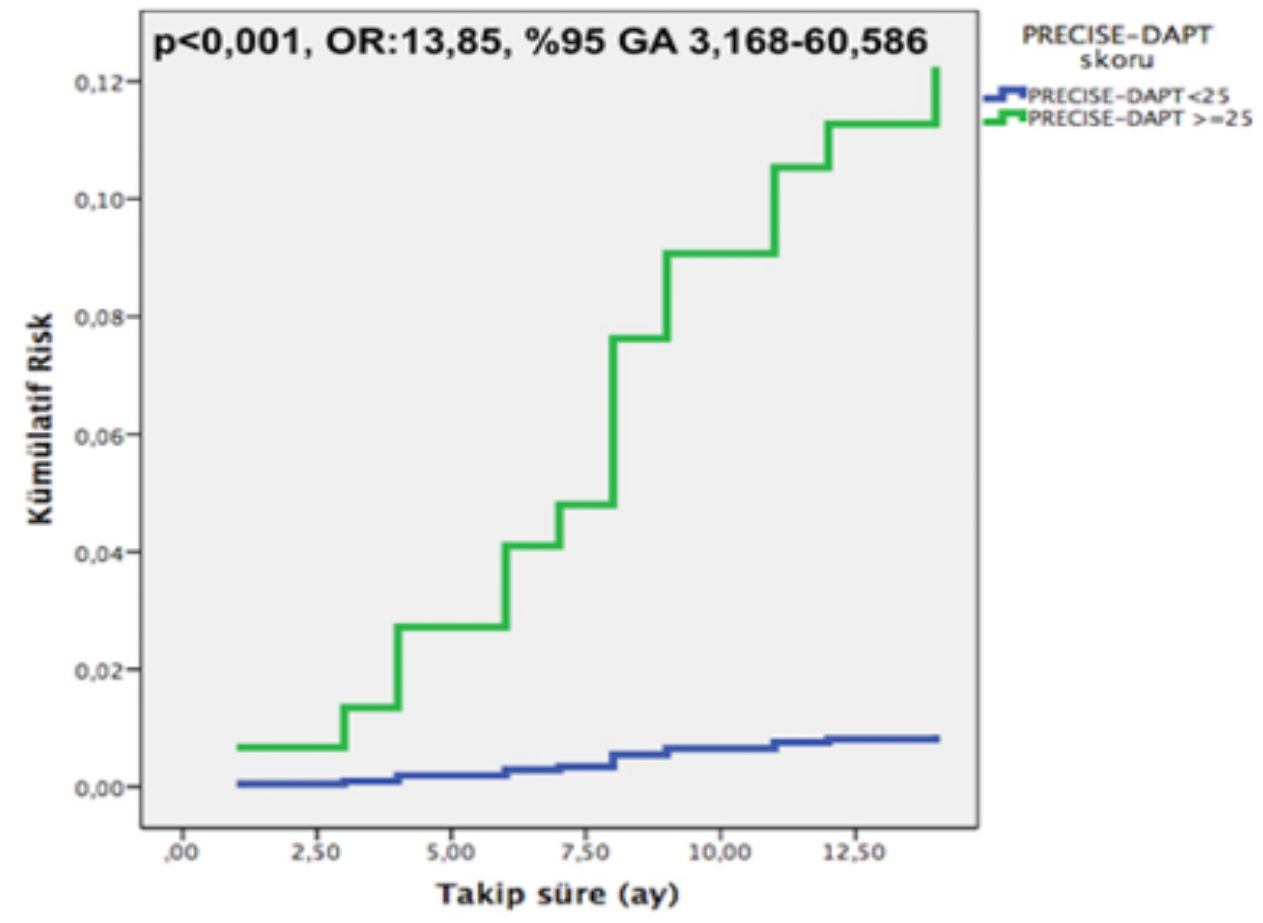

Şekil 1. Yüksek PRECISE-DAPT skoru ve ciddi kanama riski açısından univariate Cox regresyon analizi grafiği.

Tablo 3. Ciddi kanama gerçekleşen ve gerçekleşmeyen hastaların özellikleri.

\begin{tabular}{|c|c|c|c|}
\hline Özellik & $\begin{array}{l}\text { Ciddi kanama var } n=17 \\
\text { Ort } \pm S D / \%(n)\end{array}$ & $\begin{array}{l}\text { Ciddi kanama yok n=349 } \\
\text { Ort } \pm S D / \% \text { (n) }\end{array}$ & $p$ değeri \\
\hline Takip süre (ay) & $18,0 \pm 5,3$ & $17,55 \pm 4,77$ & 0,706 \\
\hline Yaş (yıl) & $65 \pm 7$ & $60 \pm 11$ & 0,064 \\
\hline Kadın Cinsiyet & $58(10)$ & $45(157)$ & 0,263 \\
\hline VKI $\left(\mathrm{kg} / \mathrm{m}^{2}\right)$ & $25 \pm 2$ & $26 \pm 3$ & 0,368 \\
\hline HT & $52,9(9)$ & $59,9(209)$ & 0,569 \\
\hline DM & $41,2(7)$ & $31,2(109)$ & 0,390 \\
\hline KBY & 0 & $6,3(22)$ & 0,286 \\
\hline Sigara & $52,9(7)$ & $56,7(198)$ & 0,758 \\
\hline Kanama öyküsü & $58,8(10)$ & $6,6(23)$ & $<0,001$ \\
\hline Mì öyküsü & $47,1(8)$ & $18,1(63)$ & 0,003 \\
\hline Trombosit & $237 \pm 100$ & $242 \pm 77$ & 0,471 \\
\hline PPI kullanımı & $76,5(13)$ & $73,4(256)$ & 0,776 \\
\hline AKS & $76,5(13)$ & $81,7(285)$ & 0,591 \\
\hline PRECISE-DAPT skoru & $40,59 \pm 14,70$ & $23,80 \pm 20$ & $<0,001$ \\
\hline PRECISE DAPT $\geq 25$ & $88,2(15)$ & $33,5(117)$ & $<0,001$ \\
\hline DAPT skoru & $1,65 \pm 0,99$ & $1,89 \pm 1,32$ & 0,392 \\
\hline $\mathrm{DAPT} \geq 2$ & $58,8(10)$ & $62,8(219)$ & 0,744 \\
\hline
\end{tabular}

(AKS: Akut koroner sendrom, DM, diyabetes mellitus, KBY: Kronik böbrek yetmezliği, Mi: miyokard infarktüsü, PPI: Proton pompa inhibitörü, VKI: Vücut kitle indeksi) 
Tablo 4. Stent trombozu gerçekleşen ve gerçekleşmeyen hastaların özellikleri.

\begin{tabular}{|c|c|c|c|}
\hline Özellik & $\begin{array}{l}\text { Stent trombozu var } n=20 \\
\text { Ort } \pm \text { SD } / \%(n)\end{array}$ & $\begin{array}{l}\text { Stent trombozu yok } n=346 \\
\text { Ort } \pm \text { SD } / \%(n)\end{array}$ & p değer \\
\hline Takip süre (ay) & $18,25 \pm 4,88$ & $17,55 \pm 4,80$ & 0,538 \\
\hline Yaş (yıl) & $57 \pm 7$ & $61 \pm 11$ & 0,126 \\
\hline Kadın Cinsiyet & $30(6)$ & $46,5(161)$ & 0,149 \\
\hline VKI $\left(\mathrm{kg} / \mathrm{m}^{2}\right)$ & $26 \pm 3$ & $26+2$ & 0,380 \\
\hline HT & $70(14)$ & $59(204)$ & 0,328 \\
\hline DM & $40(8)$ & $31,2(108)$ & 0,412 \\
\hline KBY & 0 & $6,3(22)$ & 0286 \\
\hline Sigara & $90(18)$ & $54,6(189)$ & 0,002 \\
\hline $\mathrm{PAH}$ & $0(0)$ & $5,2(18)$ & 0,296 \\
\hline PKG öyküsü & $35(7)$ & $19,7(68)$ & 0,098 \\
\hline KABG öyküsü & $0(0)$ & $1,2(4)$ & 1,000 \\
\hline Kanama öyküsü & 0 & $9,5(33)$ & 0,148 \\
\hline Trombosit & $246 \pm 119$ & $237 \pm 99$ & 0,951 \\
\hline PPI kullanımı & $85(17)$ & $72,8(252)$ & 0,231 \\
\hline LAD & $80(16)$ & $42,5(147)$ & 0,027 \\
\hline$C X$ & $10(2)$ & $28(97)$ & 0,151 \\
\hline $\mathrm{RCA}$ & $10(2)$ & $31,8(110)$ & 0,001 \\
\hline Diğer* & $0(0)$ & $9,2(32)$ & 0,514 \\
\hline Stent çapı $<3,0 \mathrm{~mm}$ & $55(11)$ & $55,8(153)$ & 0,651 \\
\hline Stent uzunluk (mm) & $19,90 \pm 4,44$ & $20,14 \pm 6,33$ & 0,818 \\
\hline İKS & $70(14)$ & $71,3(247)$ & 0,860 \\
\hline İIA dışı stent & $5(1)$ & $10,4(36)$ & 0,436 \\
\hline AKS & $100(20)$ & $80,3(278)$ & 0,028 \\
\hline DAPT skoru & $3,10 \pm 1,25$ & $1,81 \pm 1,27$ & $<0,001$ \\
\hline $\mathrm{DAPT} \geq 2$ & $90(18)$ & $57,7(211)$ & 0,009 \\
\hline
\end{tabular}

(AKS: Akut koroner sendrom, BMS: Çıplak metal stent, CX: Sirkümfleks arter, DES: İlaç salınımlı stent, DM, diyabetes mellitus, GiA: Geçici iskemik atak, KAH: Koroner arter hastalığı, KBY: Kronik böbrek yetmezliği, LAD: Sol ön inen arter, LMCA: Ana koroner arter, PAH: Periferik arter hastalığı, PKG: Perkütan koroner girişim PPI: Proton pompa inhibitörü, VKI: Vücut kitle indeksi) 


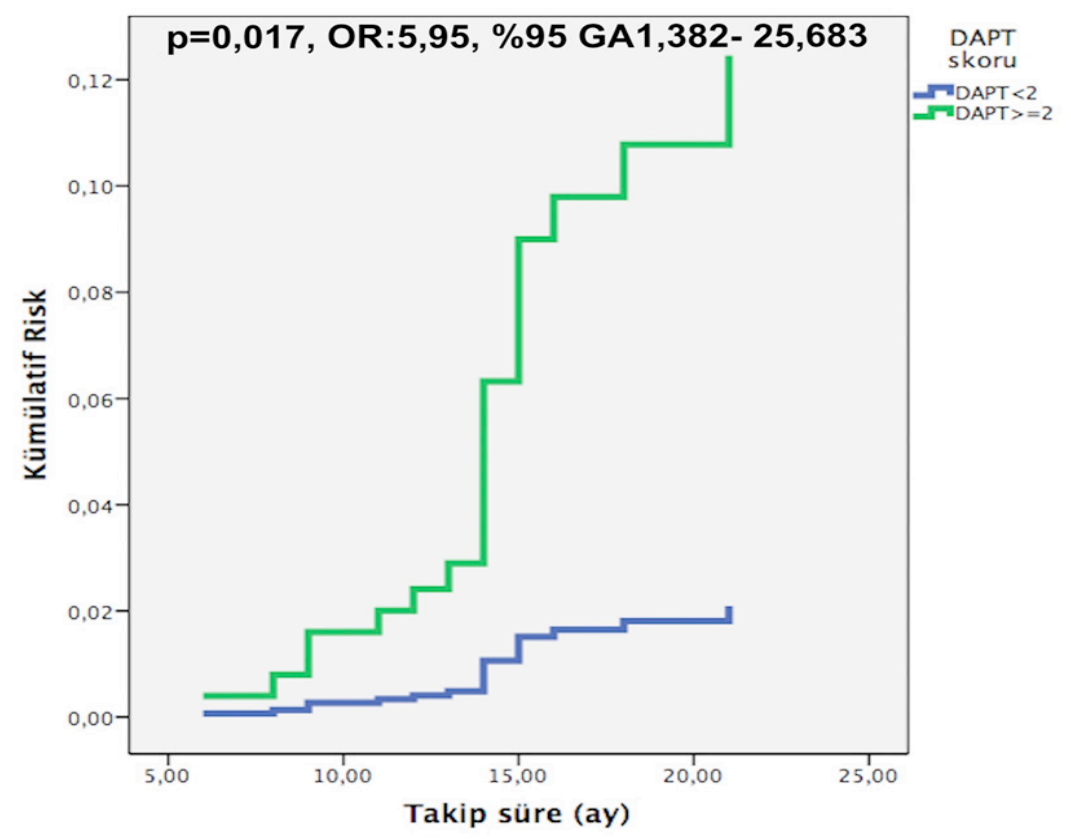

Şekil 2. Yüksek DAPT skoru ve stent trombozu riski açısından univariate Cox regresyon analizi grafiği.

uzadıkça trombotik olayların kısmen azalsa da kanama riskinin arttığını göstermektedir [7, $8,14,15]$. Genel olarak kanama ve tromboz risklerinin beraber seyrettiği düşünülse de İTT tedavisinden gerçek anlamda fayda görecek hastaları belirlemek için ESC risk skorlarının kullanılmasını önermektedir [1, 6]. PRECISEDAPT ve DAPT skorlarının randomize kontrollü çalışma verilerinden oluşturulduğu ve gerçek yaşam validasyonunun olmadığı bilinmektedir $[4,9]$. Mevcut çalışma bu skorlama sistemlerinin gerçek yaşam verileri ile kötü sonlanımlar olan stent trombozu ve ciddi kanama ile ilişkisini doğrulamaya çalışması nedeniyle özgündür. Ayrıca gerçek yaşam pratiğinde IATT stratejilerinde bu skorların kullanılmadığı için hem tromboz hem de kanama açısından hastalara ek riskler yüklendiğini göstermektedir.

DAPT skoru, DAPT çalışmasından üretilmiş olup bu çalışmada İKS takılmış hastalarda 1 yıldan sonra IATT ile sadece ASA tedavisi karşılaştırılmıştır [8, 9]. Bu çalışmada hastaların tamamında IKS mevcut ancak DAPT çalışmasında yaklaşık \%40 oranında birinci jenarasyon İKS'ler kullanılmıştır ve diğer birçok çalışmada da eski jenerasyon stentler kullanılmıştır [8, 14, 16, 17]. Eski jenerasyon stentlerde özellikle gecikmiş endotelizasyona bağlı olarak çok geç stent trombozu riskinin daha yüksek olduğu bilinmektedir [18,
19]. Mevcut çalışmada \%69,9 oranında hastalarda İKS mevcuttur ve takılan İKS'lerin hepsi everolimus ya da zotarolimus salınımı sağlayan ikinci jenerasyon stentlerdir. Tamamı AKS hastalarından oluşan PEGASUS (LongTerm Use of Ticagrelor in Patients with Prior Myocardial Infarction) çalışmasında da ve diğer çalışmaların alt grup analizlerinde de gösterildiği gibi iskemik olaylar açısından en yüksek riskli olan hasta gruplarından biri AKS öyküsü olanlardır [17]. AKS tanılı hasta DAPT çalışmasında \%50'nin altında iken mevcut çalışmada bu oran çok daha yüksektir $(\% 81,4)$. Tüm bu nedenlerle hasta popülasyonu ve kullanılan stent teknolojisi açısından mevcut çalışma grubu DAPT çalışmasına göre gerçek yaşam pratiğini daha iyi kapsamaktadır ve bu hasta grubunda da stent trombozu gelişen hastalarda DAPT skoru anlamlı olarak daha fazla izlenmiştir. Univariate analizlerde de yüksek DAPT skorunun 13 kata varan oranlarda artmış geç ve çok geç stent trombozu ile ilişkili olduğu gösterilmiştir.

Mevcut çalışma ayrıca günlük pratikte özellikle birinci yıldan sonra hastalarda DAPT skorunun yüksek PRECISE-DAPT skorunun düşük olmasına rağmen uzamış IATT kullanımının düşük olduğunu göstermiştir ve 1 yıldan sonra stent trombozu gelişen hastaların \%85'inin DAPT skoru yüksekken bu hastaların 
10'unda 1. yılın sonunda IATT kesilmiş ve tek ASA almaktayken stent trombozu gelişmiştir. $\mathrm{Bu}$ hastaların tamamında AKS tanısı vardı ve \%70'ine ikinci jenerasyon İKS implante edilmişti. Bu sonuç DAPT çalışması verileriyle de uyumludur. DAPT çalışmasında da uzamış IATT'den en çok fayda gören hasta grubu AKS olanlar olarak izlenmiştir [8]. On iki ay ve sadece 1-3 ay IATT tedavilerini karşılaştıran çalışmalarda ise hastalarda IATT süresi uzarken ciddi kanama oranları artmış, ancak iskemik olayların önlenmesinin beklendiği kadar olmadığı gösterilmiştir [7, 15]. Mevcut çalışma ve DAPT çalışması ile diğer negatif çalışmalar arasındaki en temel farklılık tromboz açısından en yüksek riskli AKS hastalarının bu çalışmalarda düşük oranda yer almasıdır.

PKG sonrası özellikle AKS sonrası hastane yatış dönemini içeren kanama risk skorları olsa da hastane dışı kanamaları tahmin etmek için risk skoru azdır [20, 21]. PRECISE-DAPT skoru 8 çok merkezli klinik çalışmadaki hastanın verileri üzerinden geliştirilirken PLATO (Platelet Inhibition and Patient Outcomes) çalışması gibi başka klinik çalışmadaki hastalar üzerinden kontrolü yapılarak hastane dışı kanamaları öngörmeyi hedeflemektedir [4, 22]. DAPT skoru gibi bu skorun da gerçek yaşamda geçerliliği kanıtlanmamıştır. Mevcut çalışma PKG sonrası IATT alan ciddi kanama gelişen hastalarda bu skorun anlamlı olarak yüksek olduğunu ve 5 kat artmış riskle ilişkili olduğunu göstermiştir. PRECISE-DAPT çalışmasının hem artısı hem de kısıtlıı̆̆ı olabilecek olan P2Y12 tedavilerindeki çeşitlilik mevcut çalışmada da mevcuttur. Skor geliştirilirken kullanılan hastaların birçoğu klopidogrel kullanırken, validasyondaki PLATO çalışmasında hastalar hem klopidrogel hem de tikagrelor kullanmaktadır. Mevcut çalışmada da hastaların \%35'i tikagrelor alırken sadece 1 hasta prasugrel kullanmaktadır. Ayrıca PLATO çalışmasında sadece AKS hastaları mevcuttur ve daha önce GiS kanaması olan hastalar da dahil edilmişti. Mevcut çalışma daha önce belirtildiği gibi yüksek oranda AKS hastası mevcuttur ve hastaların \%9'unda daha önce kanama öyküsü mevcuttur. PRECISE-DAPT skoru kanama olaylarını değerlendirirken TIMI (Thrombolysis in myocardial infarction) kanama derecelendirmesi kullanmış ve PLATO çalışmasında TIMl'ye göre yapılan analizde kanama olaylarının öngörmede yetersiz olduğu saptanınca klinik kanama olaylarını tanımlamada daha açık ve etkili olan mevcut çalışmadaki gibi BARC 3 ve üstü olaylara göre analiz yapılmıştır ve PRECISE-DAPT skorunun etkinliği gösterilmiştir [4]. Kısacası mevcut çalışma verileri de PRECISE-DAPT skoru çalışmalarına benzerdir ve gerçek yaşam hastalarında da skorun ciddi kanama olaylarıyla ilişkisini göstermiştir. Ayrıca özellikle ciddi kanama gelişen hastalar IATT süreleri PRECISEDAPT skoruna göre değerlendirildiğinde BARC 3 ve üstü kanama gelişen 17 hastadan 10'unda skoru yüksek olmasına rağmen 6 aydan uzun IATT alırken olay gelişmiştir. ESC kılavuzu bu konuda hastaların AKS ya da stabil koroner arter hastalığı olmasının dışında PRECISE-DAPT gibi kanama riskini gösteren skoru yüksekse uygun olan en kısa sürede (Stabil koroner hastalığı ya da AKS hastalarında 6 ayı geçmeden) IATT kesilmesi gerektiğini önermektedir [1, 23]. Mevcut çalışma retrospektif olsa da bu hastalarda PRECISE-DAPT skoru kullanılarak IATT süresi belirlenseydi kanama olaylarının azaltılabileceğini düşündürmektedir.

Kanama ve iskemik olaylar açısından yüksek riskli AKS hastalarının \%81,4 oranında bulunduğu mevcut çalışmada hem ciddi kanama gelişen hem de stent trombozu gelişmiş hasta grupları karşılaştırıldığında yaş, DM, HT gibi risk faktörleri açısından istatistiksel olarak anlamlı farklılık izlenmezken, DAPT ve PRECISEDAPT skorlarının anlamlı olarak farklı olması risk faktörlerinin tek başına değil, tüm risk faktörlerinin kümülatif etkisi sonucu olayların geliştiğini ve bu sonlanımların ancak risk skorları gibi bütüncül değerlendirme yöntemleri ile öngörülebileceği hipotezini desteklemesi açısından çalışma sonuçları anlamlıdır.

Mevcut çalışmada stent trombozu \%5,5 oranında, kanama da $\% 4,6$ oranında görülürken bu oranlar DAPT çalışmasının stent trombozu ve majör advers kardiyak olaylar için yaklaşık $\% 2$, ciddi kanama için \%3'ün altındaki oranları ile karşılaştırıldığında görece yüksek olduğu izlenmiştir [8]. Ancak DAPT çalışmasında perkütan girişim sonrası 1 yılda hastalar olay geçirmez ise çalışmaya alınmışlardır. Mevcut çalışmaya benzer olarak AKS hastalarının alındığı PEGASUS çalışmasında da TIMI majör kanama \%2,6, Mi ise yaklaşık \%4,5'dir [17]. Yakın zamanda yayınlanan 1 yıldan kısa IATT çalışmalarından STOP-DAPT 2 (Effect of 1-Month Dual Antiplatelet Therapy Followed 
by Clopidogrel vs 12-Month Dual Antiplatelet Therapy on Cardiovascular and Bleeding Events in Patients Receiving PCI) ve SMART-CHOICE (Effect of P2Y12 Inhibitor Monotherapy vs Dual Antiplatelet Therapy on Cardiovascular Events in Patients Undergoing Percutaneous Coronary Intervention) çalışmalarında olay oranları daha düşüktür bunun nedeni ise bu çalışmalarda AKS tanılı hasta oranlarının daha az olması ve açık etiketli çalışmalar olması nedeniyle yüksek riskli hastaların alınmamış olması olabilir [15]. Ayrıca kanama öyküsü olan hastalar birçok çalışmadan dışlanırken mevcut çalışmada \%9 oranında daha önce kanama öyküsü olan hasta vardır.

\section{Çalışmanın kısıtlılıkları}

Çalışmanın en temel kısıtlılığı kısmi retrospektif tasarımı ve üçüncü basamağa başvuran hastaların alınmasıdır. Çalışma merkezinin referans hastane konumu ve olasılıkla riskli hastaların buraya başvurması özellikle çalışmada yer almayan kararsız angına pektoris hasta grubunun ve diğer düşük riskli hastaların çalışmada temsilini kısıtlamıştır. Merkeze başvuru temel alındığı için perkütan koroner girişim sonrası kardiyovasküler ya da başka nedenle mortalite gelişen hastalar değerlendirilememiştir. Tedavide bir değişiklik söz konusu olmaması nedeniyle medikal tedavilerde skorlara göre yapılacak değişikliğin sonuçlarını değerlendirmek mümkün değildir. Ayrıca hastalarda Tikagrelor ve Prasugrel kullanımı olması gerekenden düşüktür, hastalarda hangi gerekçelerle hangi P2Y12 çeşidinin başlandığı ya da değiştirildiği elde edilen tıbbi kayıtlarda yer verilmediği için bilinmemektedir. Ancak literatürdeki benzer çalışmalar değerlendirildiğinde birçoğunda mevcut çalışmadakine benzer şekilde heterojen P2Y12 kullanılmıştır. Referans çalışmalar göz önüne alındığında çalışmadaki hasta sayısı kısıtlı gibi görünse de gerçek yaşam pratiğini yansıtması ve yukarıda bahsedilen nedenlere bağlı olarak olay sayısı yüksektir. Bu durum da gruplar arası karşılaştırma yapmak için çalışmanın istatistiksel gücünü arttırmaktadır.

Sonuç olarak, PRECISE-DAPT ve DAPT skoru gerçek yaşamda perkütan koroner girişim yapılmış ve takip edilen hasta grubunda da iskemik olay ve ciddi kanamalarla ilişkilidir. Günlük pratikte IATT süresinin belirlenmesinde bu skorlar kullanılmamaktadır ve hastalar olasılıkla intiyaçları olan sürelerden daha uzun ya da daha kısa İATT almaktadır. Bu durumun da stent trombozu ve ciddi kanama gibi istenmeyen sonlanımları arttırdığı düşünülmektedir.

Çıkar ilişkisi: Yazarlar çıkar ilişkisi olmadığını beyan eder.

\section{Kaynaklar}

1. Valgimigli M, Bueno H, Byrne RA, et al. 2017 ESC focused update on dual antiplatelet therapy in coronary artery disease developed in collaboration with EACTS: the task force for dual antiplatelet therapy in coronary artery disease of the European Society of Cardiology (ESC) and of the European Association for Cardiothoracic Surgery (EACTS). Eur Heart J 2017;39:213260. https://doi.org/10.1093/eurheartj/ehx419

2. Amin AP, Bachuwar A, Reid KJ, et al. Nuisance bleeding with prolonged dual antiplatelet therapy after acute myocardial infarction and its impact on health status. J Am Coll Cardiol 2013;61:2130-2138. https:// doi.org/10.1016/j.jacc.2013.02.044

3. Genereux P, Giustino G, Witzenbichler B, et al. Incidence, predictors and impact of post-discharge bleeding after percutaneous coronary intervention. J Am Coll Cardiol 2015;66:1036-1045. https://doi. org/10.1016/j.jacc.2015.06.1323

4. Costa F, Van Klaveren D, James S, et al. Derivation and validation of the predicting bleeding complications in patients undergoing stent implantation and subsequent dual antiplatelet therapy (PRECISE-DAPT) score: a pooled analysis of individual-patient datasets from clinical trials. Lancet 2017;389:1025-1034. https://doi. org/10.1016/s0140-6736(17)30397-5

5. Capodanno D, Angiolillo DJ. Tailoring duration of dapt with risk scores. Lancet 2017;389:987-989. https://doi. org/10.1016/s0140-6736(17)30591-3.

6. Howard CE, Nambi V, Jneid H, Khalid U. Extended duration of dual-antiplatelet therapy after percutaneous coronary intervention: how long is too long? J Am Heart Assoc 2019;8:e012639. https://doi.org/10.1161/ jaha.119.012639

7. Hahn JY, Song YB, Oh JH, et al. Effect of p2y12 inhibitor monotherapy vs dual antiplatelet therapy on cardiovascular events in patients undergoing percutaneous coronary intervention: the SMARTCHOICE randomized clinical trial. JAMA2019;321:24282437. https://doi.org/10.1001/jama.2019.8146

8. Mauri L, Kereiakes DJ, Yeh RW, et al. Twelve or 30 months of dual antiplatelet therapy after drug-eluting stents. N Engl J Med 2014;371:2155-2166. https://doi. org/10.1056/NEJMoa1409312 
9. Yeh RW, Secemsky EA, Kereiakes DJ, et al. Development and validation of a prediction rule for benefit and harm of dual antiplatelet therapy beyond 1 year after percutaneous coronary intervention. JAMA 2016;315:1735-1749. https://doi.org/10.1001/ jama.2016.3775

10. Dapt risk calculator. Available at: https://www.acc.org/ tools-and-practice-support/mobile-resources/features/ dapt-risk-calculator accessed data 10 Ekim 2019

11. PRECISE-DAPT risk calculator. Available at: http:// www.precisedaptscore.com/predapt/webcalculator. html. accessed data i 10 Ekim 2019

12. Cutlip DE, Windecker $S$, Mehran R, et al. Clinical end points in coronary stent trials. Circulation 2007;115:2344-2351. https://doi.org/doi:10.1161/ CIRCULATIONAHA.106.685313

13. Mehran R, Rao SV, Bhatt DL, et al. Standardized bleeding definitions for cardiovascular clinical trials. Circulation 2011;123:2736-2747. https://doi.org/ doi:10.1161/CIRCULATIONAHA.110.009449

14. Helft G, Steg PG, Le Feuvre C, et al. Stopping or continuing clopidogrel 12 months after drug-eluting stent placement: the OPTIDUAL randomized trial. Eur Heart J 2016;37:365-374. https://doi.org/10.1093/ eurheartj/ehv481

15. Watanabe $H$, Domei $T$, Morimoto $T$, et al. Effect of 1-month dual antiplatelet therapy followed by clopidogrel vs 12-month dual antiplatelet therapy on cardiovascular and bleeding events in patients receiving pci: the STOPDAPT-2 randomized clinical trial. JAMA 2019;321:2414-2427. https://doi. org/10.1001/jama.2019.8145

16. Lee CW, Ahn JM, Park DW, et al. Optimal duration of dual antiplatelet therapy after drug-eluting stent implantation: A randomized, controlled trial. Circulation 2014;129:304-312. https://doi.org/10.1161/ circulationaha.113.003303

17. Bonaca MP, Bhatt DL, Cohen M, et al. Long-term use of ticagrelor in patients with prior myocardial infarction. N Engl J Med 2015;372:1791-1800. https://doi. org/10.1056/NEJMoa1500857

18. Virmani R, Guagliumi G, Farb A, et al. Localized hypersensitivity and late coronary thrombosis secondary to a sirolimus-eluting stent: should we be cautious? Circulation 2004;109:701-705. https://doi. org/10.1161/01.Cir.0000116202.41966.D4

19. Sarno G, Lagerqvist B, Frobert O, et al. Lower risk of stent thrombosis and restenosis with unrestricted use of 'new-generation' drug-eluting stents: a report from the nationwide swedish coronary angiography and angioplasty registry (SCAAR). Eur Heart J 2012;33:606-613. https://doi.org/10.1093/eurheartj/ ehr479
20. Subherwal S, Bach RG, Chen AY, et al. Baseline risk of major bleeding in non-st-segment-elevation myocardial infarction: the CRUSADE (can rapid risk stratification of unstable angina patients suppress adverse outcomes with early implementation of the ACC/AHA guidelines) bleeding score. Circulation 2009;119:1873-1882. https://doi.org/10.1161/circulationaha.108.828541

21. Flores-Rios X, Couto-Mallon D, Rodriguez-Garrido J, et al. Comparison of the performance of the crusade, acuity-horizons, and action bleeding risk scores in stemi undergoing primary pci: insights from a cohort of 1391 patients. Eur Heart J Acute Cardiovasc Care 2013;2:1926. https://doi.org/10.1177/2048872612469885

22. Wallentin L, Becker RC, Budaj A, et al. Ticagrelor versus clopidogrel in patients with acute coronary syndromes. N Engl J Med 2009;361:1045-1057. https://doi.org/10.1056/NEJMoa0904327

23. Neumann FJ, Sousa-Uva M, Ahlsson A, et al. 2018ESC/ EACTS guidelines on myocardial revascularization. Eur Heart J 2018;40:87-165. https://doi.org/10.1093/ eurheartj/ehy394

Etik onayı: Çalışma için çalışmanın yürütüldüğü, Ege Üniversitesi Tıbbi Araştırmalar Etik Kurulu'nun 30.05.2019 tarih ve E.166650 sayılı kararı ile onay alınmıştır. 